\title{
Protective Effects of Orlistat on Lipid Profile, Cardiac Oxidative Stress Biomarkers and Histology in High-fat Diet-induced Obese Rats
}

\author{
Othman ZA $A^{a, c}$, Wan Ghazali WS ${ }^{a}$, Noordin $L^{a}$, Omar $N^{a}$, Mohd. Yusof $N A^{b}$, Mohamed $M^{a, d, *}$ \\ ${ }^{a}$ Department of Physiology, School of Medical Sciences, Universiti Sains Malaysia, 16150 Kubang Kerian, \\ Kelantan, Malaysia \\ bepartment of Anatomy, School of Medical Sciences, Universiti Sains Malaysia, 16150 Kubang Kerian, \\ Kelantan, Malaysia \\ 'Faculty of Medicine, Universiti Sultan Zainal Abidin, 20400, Kuala Terengganu, Terengganu, Malaysia \\ dUnit of Integrative Medicine, School of Medical Sciences, Universiti Sains Malaysia, 16150 Kubang Kerian, \\ Kelantan, Malaysia
}

\section{ABSTRACT}

Introduction: Orlistat is a widely used drug in treating obesity as it promotes weight reduction. The aim of this study was to determine the protective effects of orlistat $(10 \mathrm{mg} / \mathrm{kg} / \mathrm{day})$ on cardiovascular parameters and oxidative stress biomarkers in high-fat diet (HFD)-induced obese rats. Methods: Twenty-four male rats Sprague Dawley rats were divided into three groups and fed with normal diet (N), HFD and HFD with orlistat $(\mathrm{HFD}+0)$. Orlistat was administered daily by oral gavage and after six weeks, all rats were sacrificed. Results: Administration of orlistat along with HFD (HFD+O) has brought significant decreases in Lee obesity index and LDL level compared to HFD group. Activities of cardiac superoxide dismutase (SOD), glutathione peroxidase (GPx) and catalase (CAT) were significantly higher, whereas level of oxidised LDL was significantly lower in HFD+O group compared to HFD group. HFD group had significantly higher necrotic patch area in myocardium while minimal histological changes were seen in HFD+O group. Conclusion: This study may suggest that administration of orlistat at $10 \mathrm{mg} / \mathrm{kg} /$ day for 6 weeks may have protective effects against the changes on Lee obesity index, lipid profiles, cardiac oxidative stress biomarkers and histology of myocardium in HFD-induced obese rats possibly through its hypolipidaemic and antioxidant actions.

KEYWORDS: orlistat, obesity, cardiovascular, lipid profile, oxidative stress

\section{INTRODUCTION}

Obesity has been declared as a global public health concern and it has been documented over 115 million people in the world are suffering from obesity-related problems. ${ }^{1}$ The global prevalence of obesity is tremendously worrying as obesity is projected to rise from 396 million in 2005 to 573 million in $2030 .^{2}$ Obesity is closely related to cardiovascular risk diseases such as hyperlipidemia, hypertension and coronary artery disease. ${ }^{3}$

Corresponding Author:

Assoc. Prof. Dr. Mahaneem Mohamed, Department of Physiology,

School of Medical Sciences,

Universiti Sains Malaysia,

16150 Kubang Kerian, Kelantan, Malaysia.

Tel No : +6097676158

Email: mahaneem@usm.my
Previous study has shown that administration of highfat diet (HFD) for 14 weeks successively induced obesity and alters normal morphological function of heart and liver in male Sprague-Dawley rats due to lipid accumulation process. ${ }^{4}$

Pathogenesis of obesity-related disease is believed to be as a consequence of abundance of free radicals which can react with macromolecules in animal or human by affecting proteins, carbohydrates, lipid, and DNA sequence, which subsequently debilitate the normal cell function. ${ }^{5,6}$ Presence of naturally defence antioxidant enzymes such as superoxide dismutase (SOD), glutathione peroxidase (GPx) and catalase (CAT) have been shown to combat oxidative stress by reducing lipid peroxidation process shown by low malondialdehyde (MDA) level in HFD-induced obese rats. $^{7}$ 
Pharmacological approach is one of the adjunct therapies applied by health professionals other than dietary and lifestyle changes. Orlistat is a noncentrally acting drug and has been widely used as it reduces $30 \%$ of dietary fat absorption by inhibiting gastropancreatic lipase in the stomach and intestine, respectively. ${ }^{8}$ It is applicable for patients with body mass index (BMI) of more than $40 \mathrm{~kg} / \mathrm{m}^{2}$ and those who suffered from $\geq 2$ obesity-related medical conditions including coronary heart disease, type 2 diabetes mellitus, hypertension, dyslipidemia, cerebrovascular disease, severe osteoarthritis and sleep apnea. ${ }^{9}$ Orlistat has been shown to reduce total cholesterol and low-density lipoprotein $(L D L)^{10}$ and its side effects include oily fecal, diarrhoea, increased flatulence and abdominal discomfort. ${ }^{11}$

Significant reduced $\mathrm{BMI}$ and increased serum MDA level are observed in obese patients treated with orlistat for 6 months. ${ }^{12}$ Orlistat treatment for 6 weeks also significantly reduces liver MDA level and increases liver SOD, GPx and CAT activities in rats fed with HFD compared to control group. ${ }^{13}$ In addition, treatment of orlistat induces significant weight loss and improvements in left ventricular diastolic function and in symphatovagal balance among severely obese subjects with diabetes. ${ }^{14}$

However, no study has been reported on the protective effect of orlistat against cardiac oxidantantioxidant status and the histology of myocardium in obesity. Therefore, this study aimed to determine the effects of orlistat administration on some cardiovascular parameters such as Lee obesity index, total food and calorie intake, lipid profile, cardiac oxidant-antioxidant status and histology of myocardium in HFD-induced obese rats.

\section{MATERIALS AND METHODS}

\section{Materials}

Orlistat was purchased from Aslene, Malaysia. Hematoxylin, eosin and formaldehyde were purchased from Richard-Allan Scientific (USA), Sigma -Aldrich (USA) and Merck (Germany), respectively. Cholesterol powder was purchased from Nacalai Tesque (Japan). Assay kits for CAT, glutathione peroxidase (GPX), SOD and total protein were purchased from EnzyChromTM (USA). Assay kits for malonaldehyde and oxidized LDL (oxLDL) were purchased from Northwest Life Sciences (USA) and
Cloud Corne (USA), respectively.

\section{Normal and high-fat diet (HFD)}

Normal chow diet comprised of standard Altromin pellet, which was purchased from Animal Research and Service Centre (ARASC), Universiti Sains Malaysia (USM). The HFD regime was prepared by mixing $64 \mathrm{~g}$ of normal chow, $32 \mathrm{~g}$ of saturated fat from animal (ghee), 300 IU vitamin D3 ${ }^{15}$ and $12 \%$ of cholesterol powder. The mixture was shaped into hand-ball size before it was stored in a fridge at $4{ }^{\circ} \mathrm{C}$. HFD was prepared every other day to protect lipid from oxidation process. Normal chow diet contained $12 \%$ of fat, $24 \%$ of protein, and $64 \%$ of carbohydrate (total energy was $3.19 \mathrm{kcal} / \mathrm{g}$ ) while HFD contained $31.45 \%$ of fat, $11.59 \%$ of protein and $46.31 \%$ of carbohydrate (total energy was $5.17 \mathrm{kcal} / \mathrm{g}$ ).

\section{Experimental design}

Twenty-four male Sprague-Dawley rats (8-10 weeks old, weighing 180-230 g) were housed in a wellventilated facility with 12 -h light/dark cycle at 22-24 ${ }^{\circ} \mathrm{C}$. After acclimatization, rats were assigned into three groups $(n=8)$ i.e. Normal group $(N)$ which received normal chow diet ad libitum, HFD group which received HFD alone, and $\mathrm{HFD}+\mathrm{O}$ group which received $\mathrm{HFD}$ and orlistat at $10 \mathrm{mg} / \mathrm{kg} / \mathrm{day}$ (HFD+O) based on previous study. ${ }^{16}$ Body weight and food intake were measured every two days and daily, respectively.

All experimental protocols were performed according to guidelines from Animal and Research Centre, Universiti Sains Malaysia, Kelantan [USM/Animal Ethics Approval / 2016 /(98) (744)]. Following 6 weeks period, Lee obesity index was calculated and the rats were anaesthetized with $90 \mathrm{mg} / \mathrm{kg}$ ketamine and $5 \mathrm{mg} / \mathrm{kg}$ xylazine. Laparotomy was done to collect the blood from posterior vena cava and to harvest the heart.

\section{Measurement of Lee obesity index}

Lee obesity index was determined in this animal study. It is an index to confirm obesity whereby its value of more than 315 is considered as obese. ${ }^{17}$ It was calculated based on the formulae described by previous study ${ }^{18}$ whereby cube root of body weight (g) was divided by nose-to-anus length $(\mathrm{cm})$ of the rat. 
The blood sample was allowed to coagulate before being centrifuged. Serum was collected for measurement for lipid profile. Total cholesterol was determined by an enzymatic-colorimetric method using Architect $c$ Cholesterol Reagent kit. The indicator quinoneimine was produced from hydrogen peroxide and 4-aminoantipyrine in the presence of phenol and peroxidase. Triglyceride was determined by enzymatic hydrolysis using Architect c Triglyceride Reagent kit which converts triglyceride to free fatty acids and glycerol. Determination of high-density lipoprotein (HDL) involved elimination of chylomicron, LDL and very low-density lipoprotein by cholesterol esterase, cholesterol oxidase and catalase using Biosino Direct HDL-Cholesterol reagent kit. Measurement of LDL was determined by Friedwald formula as below: ${ }^{19}$

LDL $(\mathrm{mmol} / \mathrm{L})=$ Total cholesterol $-\mathrm{HDL}+$ Triglyceride/5].

\section{Biochemical measurement}

The heart tissue was homogenized in $10 \%$ ice-cold phosphate buffer solution before being centrifuged. The supernatant was collected and used to determine activities of SOD, GPx, and CAT. Total protein content of samples were used to express the activity of antioxidant enzymes. Levels of oxLDL and MDA were also determined.

\section{Histology of myocardium}

The heart tissue was dissected out, rinsed immediately with phosphate buffer solution and fixed in $10 \%$ formalin solution. Following fixation, the heart section was embedded in a paraffin block, sliced using microtome machine at $5 \mu \mathrm{m}$ size, and stained with Haematoxylin and Eosin solution. ${ }^{20}$

\section{Statistical analysis}

All data are expressed as mean (standard deviation). Prior to statistical analysis, all variables were checked for normal and homogeneous variance using the Levene test. The mean differences were statistically analyzed by performing one-way analysis of variance (ANOVA) test with Tukey posthoc test for multiple comparisons. $P$ value $<0.05$ was considered as statistically significant.
Effects of orlistat on Lee obesity index, weight gain, mean food intake, and calorie intake.

HFD group had significantly higher Lee obesity index and calorie intake compared to $\mathrm{N}$ group. Meanwhile, HFD+O group had significantly lower Lee obesity index compared to HFD group and had significantly higher total calorie intake compared to $\mathrm{N}$ group. No significant differences were found for weight gain and food intake among all groups (Table 1).

Table 1. Effects of orlistat on Lee obesity index, weight gain, mean food intake and calorie intake in all groups.

\begin{tabular}{|c|c|c|c|}
\hline & $\mathbf{N}$ & HFD & HFD+O \\
\hline $\begin{array}{l}\text { Lee obesity } \\
\text { index }\end{array}$ & $\begin{array}{c}310.94 \\
(2.69)\end{array}$ & $\begin{array}{c}339.87 \\
(12.82)^{a}\end{array}$ & $\begin{array}{c}320.51 \\
(12.60)^{b}\end{array}$ \\
\hline $\begin{array}{l}\text { Weight gain } \\
\text { (g) }\end{array}$ & $\begin{array}{c}98.58 \\
(39.28)\end{array}$ & $\begin{array}{l}120.09 \\
(22.80)\end{array}$ & $\begin{array}{c}105.90 \\
(22.57)\end{array}$ \\
\hline $\begin{array}{l}\text { Mean Food } \\
\text { intake } \\
\text { (g/day) }\end{array}$ & $21.11(2.68)$ & $\begin{array}{l}18.43 \\
(1.28)\end{array}$ & $\begin{array}{l}20.97 \\
(0.96)\end{array}$ \\
\hline $\begin{array}{l}\text { Calorie } \\
\text { intake } \\
\text { (Kcal/day) }\end{array}$ & $67.13(3.72)$ & $\begin{array}{c}94.91 \\
(6.59)^{a}\end{array}$ & $\begin{array}{l}107.97 \\
(4.95)^{\mathrm{a}}\end{array}$ \\
\hline
\end{tabular}

Data are presented in mean (standard deviation), $n=8$ per group.

so $P<0.05$ compared with normal group.

${ }^{\mathrm{b}} \mathrm{P}<0.05$ compared with HFD group.

One-way ANOVA followed by Tukey post-hoc test.

$\mathrm{N}$; normal, HFD; high-fat diet, HFD+O; high-fat diet and orlistat.

\section{Effects of orlistat on lipid profile}

Both total cholesterol and LDL levels were significantly higher in HFD group compared to $\mathrm{N}$ group. In HFD+O group, LDL level was significantly lower when compared to HFD group. However, no significant differences were observed on serum triglyceride and $\mathrm{HDL}$ levels among all groups (Table 2).

Table 2. Effects of orlistat on serum lipid profile in all groups.

\begin{tabular}{lccc}
\hline & $\mathrm{N}$ & HFD & HFD+O \\
\hline $\begin{array}{l}\text { Total } \\
\text { Cholesterol }\end{array}$ & 1.76 & 2.29 & 1.90 \\
(mmol/L) & $(0.19)$ & $(0.20)^{\mathrm{a}}$ & $(0.26)^{\mathrm{b}}$ \\
Triglyceride & 0.79 & 1.09 & 1.03 \\
(mmol/L) & $(0.32)$ & $(0.35)$ & $(0.36)$ \\
LDL (mmol/L) & 0.20 & 0.41 & 0.16 \\
& $(0.17)$ & $(0.22)^{\mathrm{a}}$ & $(0.10)^{\mathrm{b}}$ \\
$\mathrm{HDL}(\mathrm{mmol} / \mathrm{L})$ & 1.19 & 1.23 & 1.31 \\
\hline
\end{tabular}

Data are presented in mean (standard deviation),

$\begin{aligned} & n=8 \text { per group. } \\ & a\end{aligned}<0.05$ compared with normal group.

${ }^{b} \mathrm{P}<0.05$ compared with HFD group.

One-way ANOVA followed by Tukey post-hoc test.

$\mathrm{N}$; normal, HFD; high-fat diet, HFD+O; high-fat diet and 10 $\mathrm{mg} / \mathrm{kg} /$ day orlistat. LDL; low-density lipoprotein. HDL; high-density lipoprotein. 


\section{Effects of orlistat on oxidant-antioxidant status}

SOD activity was significantly lower and MDA level was significantly higher in HFD group compared to $\mathrm{N}$ group. Meanwhile, HFD+O group had significantly higher SOD, GPx and CAT activities, and lower oxLDL level compared to HFD group (Table 3).

Table 3. Effects of orlistat on cardiac oxidant-antioxidant status in all groups

\begin{tabular}{|c|c|c|c|}
\hline & $N$ & HFD & $\mathrm{HFD}+\mathrm{O}$ \\
\hline $\begin{array}{l}\text { Catalase } \\
\text { (U/mg protein) }\end{array}$ & $\begin{array}{c}1.03 \\
(0.29)\end{array}$ & $\begin{array}{l}0.66 \\
(0.27)\end{array}$ & $1.23(0.33)$ \\
\hline $\begin{array}{l}\text { Glutathione } \\
\text { peroxidase (U/ } \\
\text { mg protein) }\end{array}$ & $\begin{array}{l}435.69 \\
(19.00)\end{array}$ & $\begin{array}{l}431.58 \\
(3.50)\end{array}$ & $\begin{array}{c}566.66 \\
(16.19)^{\mathrm{a}, \mathrm{b}}\end{array}$ \\
\hline $\begin{array}{l}\text { Superoxide } \\
\text { dismutase (U/mg } \\
\text { protein) }\end{array}$ & $\begin{array}{l}2.55 \\
(0.69)\end{array}$ & $\begin{array}{c}1.55 \\
(0.34)^{a}\end{array}$ & $2.47(0.54)$ \\
\hline $\begin{array}{l}\text { Malondialdehyde } \\
\text { (nmol/mg } \\
\text { protein) }\end{array}$ & $\begin{array}{c}0.17 \\
(0.02)\end{array}$ & $\begin{array}{l}0.24 \\
(0.05)^{a}\end{array}$ & $0.19(0.46)$ \\
\hline $\begin{array}{l}\text { Oxidised LDL } \\
\text { (pg/mL) }\end{array}$ & $\begin{array}{l}261.79 \\
(49.85)\end{array}$ & $\begin{array}{l}304.27 \\
(66.32)\end{array}$ & $\begin{array}{l}210.00 \\
(27.01)^{b}\end{array}$ \\
\hline
\end{tabular}

Data are presented in mean (standard deviation), $n=8$ per group.

${ }^{a} \mathrm{P}<0.05$ compared with normal group.

${ }^{b} \mathrm{P}<0.05$ compared with HFD group .

One-way ANOVA followed by Tukey post-hoc test.

$\mathrm{N}$; normal, HFD; high-fat diet, HFD+O; high-fat diet and $10 \mathrm{mg} / \mathrm{kg} /$ day orlistat.

\section{Effects of orlistat histology of myocardium}

Histological appearance of myocardium tissue showed the presence of significantly large necrotic patch area in HFD group compared to $\mathrm{N}$ group. However, in $\mathrm{HFD}+\mathrm{O}$ group, these changes were minimally seen (Figure 1 and Table 4).

Table 4. Quantitative analysis of necrotic area in all groups

\begin{tabular}{lccc}
\hline & $\mathrm{N}$ & HFD & HFD+O \\
\hline Necrotic & $0.00(0.00)$ & $0.54(0.14)^{\mathrm{a}}$ & $0.00(0.00)^{\mathrm{b}}$ \\
area $\left(\mathrm{mm}^{2}\right)$ & & & \\
\hline
\end{tabular}

Orlistat significantly reduced necrotic area in myocardial tissue of rats fed with HFD. Data are presented in mean (standard deviation). $\mathrm{n}=8$.

${ }_{a} P<0.05$ compared with normal group.

${ }^{b} \mathrm{P}<0.05$ compared with HFD group.

One-way ANOVA followed by Tukey post-hoc test.

$\mathrm{N}$; normal, HFD; high-fat diet, HFD+O; high-fat diet and $10 \mathrm{mg} / \mathrm{kg} /$ day orlistat.

\section{DISCUSSION}

There were some cardiovascular changes in male Sprague-Dawley rats following HFD ingestion for 6 weeks. Although, there was no significant changes in body weight gain and food intake, HFD regime used in the present study was able to establish a successful animal model of obesity as shown by the significantly higher Lee obesity index in HFD group compared to $\mathrm{N}$ group. Meanwhile, Lee obesity index was significantly lowered in $\mathrm{HFD}+\mathrm{O}$ group compared to HFD group which might indicate some protective effect of orlistat against obesity. Mean calorie intake in group administered with HFD (HFD and HFD+O groups) were significantly higher compared to $\mathrm{N}$ group which is similar to previous study. ${ }^{21}$ The increased total calorie intake in these HFD groups were attributed to the higher content of fat composition in HFD regime.

After 6 weeks of HFD administration, total cholesterol and LDL levels were significantly higher in HFD groups compared to $N$ group. This could be due to ingestion of higher fat content in HFD food regime used in the present study that subsequently might increase lipid metabolism pathway. Orlistat had significantly lowered levels of total cholesterol and $L D L$ as shown in HFD+O group. This finding could be due to effect of orlistat which caused excessive fecal fat loss as a result of inhibition of fat absorption in HFD-induced obese rats. ${ }^{22}$ On the other hand, both $\mathrm{HFD}$ and $\mathrm{HFD}+\mathrm{O}$ groups had insignificant changes on the levels of TG and HDL which are consistent with previous study. ${ }^{23}$

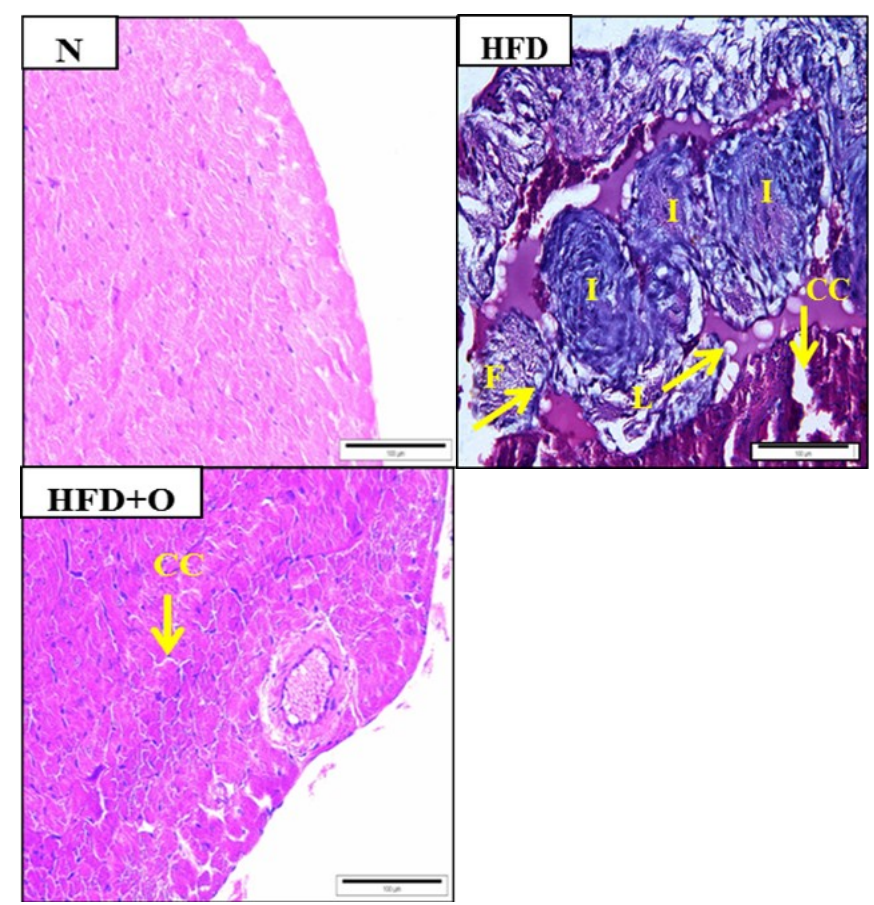

Figure 1. Histopathological sections of myocardium stained with H\&E in all groups. $\mathrm{N}$ group shows normal appearance of myocardial tissue with no pathological changes. HFD group shows presence of necrotic patch which consists of foam cells (F), inflammatory cells (I), lipid droplets (L) and wide cholesterol cleft (CC). HFD+O group shows the presence of cholesterol cleft in between the myocardial fibers. $N$, normal: HFD, high fat diet; $\mathrm{HFD}+\mathrm{O}, \mathrm{HFD}$ and $10 \mathrm{mg} / \mathrm{kg}$ orlistat. (Haematoxylin and Eosin staining, magnification $\mathrm{X} 100$, scale bar $=100 \mu \mathrm{m})$. 
Fatty acids which are the building block for lipid are susceptible to oxidation process partly through the presence of free radicals as intermediate. ${ }^{24}$ In the present study, HFD group had higher levels of cardiac MDA compared to $\mathrm{N}$ group suggesting the presence of oxidative stress in the heart following HFD intake. This oxidative stress is contributed by HFD due to the generation of free radicals which further leads to formation of lipid peroxidation. ${ }^{25}$ Involvement of lipid peroxidation product shows an evidence of the presence of toxic radicals as a consequence of obesity. ${ }^{26}$ However, the level of cardiac MDA in $\mathrm{HFD}+\mathrm{O}$ group was not significantly different from $\mathrm{N}$ group, which might suggest some protective effect against lipid peroxidation. In addition, oxLDL was significantly lower in HFD+O group than HFD group which might further suggest that orlistat is able to reduce cardiac oxidative stress level.

HFD group had significantly lowered SOD activity compared to $\mathrm{N}$ group presumably due to the presence of cardiac oxidative stress. Administration of orlistat for 6 weeks duration revealed significant increases of SOD, GPx and CAT activities compared to HFD group which are consistent with another study on the liver. ${ }^{13}$ The findings in the present study might suggest the antioxidant effect of orlistat against oxidative stress in rats fed with HFD. HFD group showed the presence of large necrotic patch area which was significantly larger compared to $\mathrm{N}$ group. On the other hand, HFD+O group showed an improvement on histological changes of myocardium tissue which showed significant smaller necrotic patch area compared to HFD group as well as higher SOD, GPX and CAT activities in HFD+O group. Several studies have proposed that inflammation is derived from accumulation of lipid in the myocardium of HFD-fed rats. ${ }^{27}$ However, it is not known whether orlistat may also improve inflammation in obesity which needs further study to determine its exact mechanism of action. The improved histological finding in $\mathrm{HFD}+\mathrm{O}$ group could be due to the protective effect of orlistat against oxidative stress as shown by lower levels of oxLDL and MDA.

\section{CONCLUSION}

The findings of the study may suggest that administration of orlistat at $10 \mathrm{mg} / \mathrm{kg} /$ day for 6 weeks had protective effects on Lee obesity index, lipid profile, cardiac oxidant-antioxidant status and histology of myocardial tissue in HFD-induced obese rats. These effects might be possibly due to its hypolipidemic and antioxidant effects which need further study to understand its exact mechanism of action.

\section{CONFLICTS OF INTEREST}

The authors declare that there are no conflicts of interest.

\section{ACKNOWLEDGEMENT}

The authors would like to thank Universiti Sains Malaysia for the financial support [USM Short Term Research University Grant (304/PPSP/61313189)].

\section{REFERENCES}

1. World Health Organization. Controlling the global obesity epidemic. Available at: http:// www.who.int/nutrition/topics/obesity/en/ index.html. Accessed Mac 2017.

2. Kelly T, Yang W, Chen CS, et al. Global burden of obesity in 2005 and projections to 2030. Int J Obes 2008; 32:1431-7.

3. Segula D. Complications of obesity in adults: a short review of the literature. Malawi Med J. 2014; 26:20-4.

4. Padmanabhan $M$ and Arumugam G. Effect of Persea americana (avocado) fruit extract on the level of expression of adiponectin and PPAR-y in rats subjected to experimental hyperlipidemia and obesity. J Complement Intgr Med 2014;11 (2):107-19.

5. Devasagayam T, Tilak JC, Boloor KK, et al. Free radicals and antioxidants in human health: current status and future prospects. J Assoc Physicians of India 2004; 52:794-804.

6. Saha D and Tamrakar A. Xenobiotics, oxidative stress, free radicals vs. antioxidants: Dance of death to heaven's life. Asian Journal of Research in Pharmaceutical Siences. 2011:1(2):36-8.

7. Charradi K, Mahmoudi M, Elkahoui S, et al. Grape seed and skin extract mitigates heart and liver oxidative damage induced by a high-fat diet in the rat: gender dependency. Can J Physiol and Pharmacol 2013; 91(12):1076-85.

8. Zhi J, Melia AT, Guerciolini R, et al. Retrospective population-based analysis of the dose-response (fecal fat excretion) relationship of orlistat in normal and obese volunteers. Clin Pharmacol Ther 1994; 56(1):82-5.

9. Snow V. Pharmacologic and surgical management of obesity in primary care: A 
clinical practice guideline from the american college of physicians. Ann Intern Med 2005; 142 (7):525-31.

10. Chaput $J$ and Tremblay A. Currently available drugs for the treatment of obesity: sibutramine and orlistat. Mini-Reviews Med Chem 2007; 7 (1):3-10.

11. Lee PC and Dixon J. Pharmacotherapy for obesity. Aust Fam Physician 2017; 46(7):472-7.

12. Yesilbursa D, Serdar Z, Serdar A, et al. Lipid peroxides in obese patients and effects of weight loss with orlistat on lipid peroxides levels. Int J Obes 2005; 29(1):142-5.

13. Bharati $\mathrm{V}$, Rengarajan RL, Radhakrishnan R, et al. Effects of a medicinal plant Macrotyloma uniflorum (Lam.) Verdc. formulation (MUF) on obesity-associated oxidative stress-induced liver injury. Saudi J Biol Sci 2018;1-7.

14. Martin J, Paquette $C$, Marceau S. et al. Impact of orlistat-induced weight loss on diastolic function and heart rate variability in severely obese subjects with diabetes. J Obes 2011; ID394658:1-8.

15. Rason N, Ramli N, Safuan S, et al. Histopathological alteration in organ structures of induced-obese rats fed with high-fat diet. Ann Microsc 2016; 15:38-48.

16. Zaitone SA and Essawy S. Addition of a low dose of rimonabant to orlistat therapy decreases weight gain and reduces adiposity in dietary obese rats. Clin Exp Pharmacol Physiology 2012;39:551-9.

17. Bellinger LL, Bernardis LL. Effect of dorsomedial hypothalamic nuclei knife cuts on ingestive behavior. Am J Physiol Integ Comp Physiol 1999; 276(6):R1772-9.

18. Novelli ELB, Diniz YS, Galhardi CM, et al. Anthropometrical parameters and markers of obesity in rats. Lab Anim 2007; 41:111-9.

19. Friedewald W, Levy R, Fredrickson D.

Estimation of the concentration of low-density lipoprotein cholesterol in plasma, without use of the preparative ultracentrifuge. Clin Chem 1972; 18(6):499-502.

20. Andrés-manzano MJ, Andrés $\mathrm{V}$, Dorado $\mathrm{B}$. Methods in mouse atherosclerosis. In: methods in molecular biology. NewYork: Springer Science+Business Media, 2015.

21. Ebaid GM, Seiva FRF, Rocha KK, et al. Effects of olive oil and its minor phenolic constituents on obesity-induced cardiac metabolic changes. Nutr J 2010; 9(46):1-9.
22. Ueshima K, Akihisa-umeno $\mathrm{H}$, Nagayoshi A, et al. A gastrointestinal lipase inhibitor reduces progression of atherosclerosis in mice fed a western-type diet. Eur J Pharmacol 2004; 501:137-42.

23. Rössner $S$, Sjostrom L, Noack R, et al. Weight loss, weight maintenance, and improved cardiovascular risk factors after 2 years treatment with orlistat for obesity. Obes Res 2000; 8(1): 49-61.

24. Shahidi $F$, Zhong Y. Lipid oxidation and improving the oxidative stability. Chem Soc Rev2010; 39(11):4067-79.

25. Sunil V, Shree N, Venkataranganna MV, et al. The anti diabetic and anti obesity effect of Memecylon umbellatum extract in high fat diet induced obese mice. Biomed Pharmacother 2017; 89:880-6.

26. Rahman K. Studies on free radicals, antioxidants, and co-factors. Clin Interv Aging 2007; 2(2):219-36.

27. Diwan V, Poudyal H, Brown L. Piperine attenuates cardiovascular, liver and metabolic changes in high carbohydrate, high fat-fed rats. Cell Biochem Biophys 2013; 67(2):297-304. 